FORUM DE OPINIŌES

\title{
Desenvolvimento: Um Desafio Social
}

Prezado Senhor Redator-Chefe da

Revista de Administração de Emprêsas

Em seu número de junho do corrente ano encontramos o artigo de Raimar Richers com o título acima. Passamos a tecer alguns comentários sôbre o artigo em pauta.

Gostariamos de dividir nosso comentário em duas partes. Inicialmente nos ateremos à tese geral de Richers e logo em seguida passaremos a itens específicos do artigo.

Parece-nos, na essência, e utilizando de nomenclatura econômica, que o Prof. Richers objeta a abordagem econômica ao desenvolvimento econômico ou seja aquela que tem na poupança, na tecnologia, e no investimento a dinâmica do processo. Opõe a isso o desenvolvimento, a incorporação das camadas marginalizadas da população, ou seja a crescente mobilização e socialização de uma sociedade ... que se projeta através da ativação dos fatôres de produção em potencial. Torna-se evidente, no desenvolver do argumento, que esta incorporação ou ativação darse-á pela redistribuição da renda entre indivíduos pertencentes ao círculo interno àqueles que necessitam de ativação ou, em 
nossos têrmos, às camadas marginalizadas da população. Em síntese, o desenvolvimento só se dará quando a renda fôr redistribuída.

Queremos chamar a atenção do Prof. Richers a uma penosa realidade econômica de que sociedade alguma tem meios de escapar. A Renda Nacional de um país pode ser tôda ela consumida e com isto o bem-estar imediato da população maximizado; mas a longo prazo, sem a reposição dos bens de produção por ela desgastados, o produto nacional será cada vez menor em periodos subsequientes. Podemos cogitar que seja subtraído do produto o suficiente para reposição dêste desgaste; com isto o produto se manterá no mesmo nível, mas a renda per capita estará em contínuo declínio à medida que a população do país esteja crescendo. Poderemos também cogitar de investimentos suficientes para manter a renda per capita em seu presente nível; para isto é necessário comprimir o consumo presente em montante suficiente para que isto se dê. No entanto, se esperamos que a renda individual esteja em ascenção ao passar o tempo, então o consumo presente, em parcela maior, temos que comprimir. Estas hipóteses taxonômicas têm como objetivo mostrar a impossibilidade de aumentar o produto nacional sem que isto implique na redução do consumo presente. Lembramos ao Prof. Richers que as classes de renda mais baixa, por necessidade, tendem a consumir a totalidade ou mais de seus vencimentos, conforme se pode observar em qualquer função de consumo levantada em perfil. Isto implica na seguinte conseqüência: qualquer tentativa de redistribuição radical da renda em favor das classes mais pobres implica no sacrifício das poupanças nacionais e conseqüente queda nos investimentos e portanto na diminuição do processo de desenvolvimento econômico à medida em que êste representa um aumento na quantidade de bens e serviços à disposição da sociedade.

Uma sociedade rica pode dar-se ao luxo de redistribuição da renda em prejuízo ao ritmo de seu crescimento econômico; uma sociedade pobre não pode fazê-lo, sob pena de nunca desqualificar-se da pecha de subdesenvolvida.

Queremos chamar a atenção ao fato de que mesmo uma sociedade socialista que tem como objetivo comunitário principal a 
abolição das classes e a eqüidade na distribuição do produto social - referimo-nos à U.R.S.S. - não teve como escapar da penosa realidade econômica a que acima fizemos referência. Para obter o ritmo de desenvolvimento econômico de que foi capaz a partir de 1917, a União Soviética precisou comprimir ainda mais o já parco consumo das massas proletárias e, principalmente, camponesas neste período que intermedeia entre aquela data e a nossa.

Pergunta-se, então, como incorporar as camadas marginalizadas da população ao sistema produtivo tal que contribuam à produção e recebam renda correspondente, renda esta que será reinjetada no ciclo de produção? Não existe caminho fácil para esta incorporação. A própria dinâmica do crescimento do círculo interno de que fala Richers, é que há de fazê-lo. A medida que o processo de investimento requeira um número maior de trabalhadores, ${ }^{1}$ êstes serão deslocados do setor de subsistência, onde não fazem falta ${ }^{2}$ e passarão a incorporar-se ao círculo interno até que êste abranja a grande maioria da população de um país. A União Soviética, de que falamos, acima, adotou esta estratégia; o Brasil e outros países em desenvolvimento, embora sob outro sistema econômico e político, estão adotando-a agora, e não vemos alternativa a outros países senão adotarem também essa estratégia.

O processo de qualificação educacional que está implícito nos caminhos apontados por Richers para as massas marginalizadas, é uma solução que, na melhor das hipóteses, ataca os sintomas da marginalização sem contribuir para sua solução. Se algum efeito tem, é o de criar maiores tensões sociais que aquelas já existentes. Um analfabeto marginalizado tem um potencial destruidor pequeno. Um $\mathrm{PhD}$ marginalizado, por falta de oportunidades de trabalho, tem um potencial destrutivo que só se limita

1 evidente que por maior capital intensivo que forem os investimentos, alguma mão-de-obra adicional será absorvida. Intensividade de capital retarda mas não anula o efeito absorvedor de mão-de-obra. Ver EckHAus, R. S. The Factor Proportion, Problem in Underdevolped Areas. The American Economic Review, setembro 1955.

2 Estamos supondo que por marginalizados, ou não incorporados ao processo produtivo, a população de que falamos nada contribui a este processo até que a êle incorporadas. Ver LEwis, Arthur W. Economic Development with Unlimited Supplies of Labor. The Manchester School, maio de 1954. 
pela imaginação. Formar PhD's, bacharéis ou mesmo alfabetizados, onde não existe mercado de trabalho para absorvê-los, é criar uma situação revolucionária da maior periculosidade. Temos que dosar os investimentos, de um lado nas instalações criadoras de emprêgo, e de outro nos investimentos educacionais. Podemos mesmo supor, e com alguma evidência factual, ${ }^{3}$ que investimentos tradicionais em capacidade produtiva, criem automaticamente os elos que à la Hirschman ${ }^{4}$ criem os investimentos educacionais necessários.

Passamos a tecer algumas considerações sôbre pontos mais específicos do ensaio de Richers.

Logo no início encontramos uma série de críticas contendo um atestado de óbito ao uso do índice de renda per capita como indicador do nivel de desenvolvimento relativo de um país. Essas críticas dizem respeito à falta de indicação da distribuição geogrăfica e social da renda ao usarmos êste índice. No parágrafo seguinte, sem nem mesmo curto espaço de luto, Richers passa a usar a própria renda per capita diferencial de regiões dentro de um país para mostrar que ela - renda per capita - nada nos indica acêrca destas diferenças.

Na página 44 fala Richers que a renda per capita nada nos indica acêrca do trabalho não remunerado em horas de lazer. Ora, a ociosidade ou o lazer que tanto diz aos países desenvolvidos, como para nós, subdesenvolvidos, é um lazer forçado - é o lazer do desemprêgo. Renda per capita baixa reflete êsse lazer e nos parece um argumento a favor de seu uso e não contra. A vantagem da renda per capita como índice do subdesenvolvimento nos parece reforçada pelas posições de Richers - regiões pobres e classes altamente desfavorecidas rebaixam a renda per capita e esta passa a refletir êste estado inauspicioso da estrutura interna da sociedade.

Richers, na página 45 de seu artigo, faz uma justificativa para uma definição temporário do objeto de estudo - o subdesenvol-

- vimento. Queremos chamar a atenção ao fato de que Richers

3 Ver a indústria automobilística nacional onde tanto a mão-de-obra especializada como os técnicos foram treinados pelo próprio setor.

- Hirschman, Albert. The Strategy of Economic Development. 
confunde duas funções da ciência positiva. Parafraseando Milton Friedman, ${ }^{5}$ a ciência positiva contém dois elementos: ela é uma linguagem e aqui o seu critério de avaliação é a clareza de suas definições, a maneira em que permite a organização e sistematização do processo de raciocínio; ela também é um corpo de hipóteses substantivas objetivando a abstração de fatôres essenciais de uma realidade complexa, e aqui, o seu critério de avaliação é mais complicado, e, para evitarmos divagações, aternos-emos ao primeiro elemento. A definição do objeto de estudo de uma ciência positiva pertence à parte que diz respeito à linguagem da ciência. Para podermos desenvolver seu estudo e formular hipóteses precisamos estar de acôrdo sôbre o que estamos discutindo. Imprecisão neste ponto nos leva a esforços dispersivos. Apresentar uma definição que poderá ser modificada a qualquer momento dependendo de onde nossas investigações nos conduzem, cria confusão através da falta de elementos precisos de investigação. Em resumo, se não sabemos o que é que nos propomos estudar, como estudá-lo?

Não compreendemos como o prof. Richers pode dizer-nos na página 59 que “... êsses produtos costumam assegurar margens unitárias de lucro bastante elevado já que se destinam a compradores de poder aquisitivo discricionário e se caracterizam por uma alta elasticidade, tanto da renda, quanto do preço" (o grifo é nosso). Se lembrarmos corretamente, a alta elasticidade-preço de um produto leva o empresário a diminuir seus preços para assegurar-se de um maior retôrno sôbre seu capital investido. Isso implica em mais baixo lucro unitário, mas em um aumento na quantidade produzida. Que os produtos de que fala Richers se caracterizam pela alta elasticidade-renda e baixa elasticidadepreço e que isso leve a preços altos e portanto a altos lucros unitários, estamos de acôrdo; mas nos têrmos colocados por Richers, aquilo nos afigura uma impossibilidade, a não ser que estejamos tratando de empresários que não objetivam a maximização de seus lucros.

Esperamos que com os elementos expostos acima, estejamos contribuindo com uma pequena parcela que seja ao louvável es-

5 FrIEdMaN, Milton. The Methodology of Positive Economics. In: Essays in Positive Economics, p. 7. 
fôrço do professor Richers em apresentar uma abordagem menos econômica ao estudo do desenvolvimento; pôsto que em sintonia com a grande maioria dos estudiosos dêste campo, longe está de nós negar a essencialidade da contribuição das outras ciências sociais ao estudo dêste tópico importantíssimo para a riqueza das nações.

DenNis Cintra Leite

\section{Resposta:}

Ao ler os comentários do jovem professor Cintra Leite, veio-me a mente uma frase de Thomas $\mathrm{H}$. Carroll: "O maior problema da comunicação é a ilusão de que ela tenha sido realizada."

De duas, uma: ou as mensagens do artigo Desenvolvimento: um Desafio Social não são suficientemente claras para que um economista profissional possa entendê-las, ou o comentarista não se empenhou em compreendê-las. Certo é que, das suas seis objeções, cinco partem de premissas ou inferências que o artigo não faz; a sexta está realmente implícita, como êle afirma; é, porém, tratada de uma maneira ao menos discutível.

Trataremos dêsses seis pontos um por um, se bem que apenas sumàriamente:

1. A tese central do artigo é errôneamente interpretada no sentido de que o desenvolvimento só se dará quando a renda fôr redistribuída. $O$ artigo fala de três tipos de ativação (instrumental, funcional e social), das quais a terceira visa, primordialmente, à reestruturação da renda. Ademais, o texto frisa: "No entanto, o objetivo principal da ativação social não deveria ser a redistribuição das rendas disponiveis, mas o despertar das fôrças latentes nas camadas subdesenvolvidas da população, a fim de que essas possam participar do processo de modernização (p. 49, grifo acrescido). Mais tarde, ao ilustrar a ativação social, à base de um exemplo numérico (p. 60-62), refiro-me exclusivamente à reestruturação, para evitar confusões com o conceito da redistribuição.

Como Cintra Leite partiu de uma interpretação errônea da tese, os argumentos que contra ela apresenta dispensam comentários. 
2. O artigo oferece seis razões para contestar a validade da renda como indicador satisfatório do grau de desenvolvimento de um país. Uma delas afirma que a renda média per capita nacional (p. 43) - ou seja, a renda média referente a um pais inteiro é uma expressão particularmente inadequada do desenvolvimento, quando o país em questão fôr grande e apresenta acentuados desequilíbrios regionais. Para ilustrar êsse argumento, cito alguns dados referentes ao Brasil. Cintra Leite, contudo, não parece ter entendido o argumento, o interpreta errôneamente e procura refutar o que não afirmei.

3. Em semelhante êrro de interpretação incorre o comentarista quando se refere ao lazer. $O$ texto afirma, simplesmente, que a renda nada revela sôbre possiveis fatôres não monetários do desenvolvimento (como, por exemplo, a troca direta de bens ou o trabalho não remunerado em horas de lazer)" (p. 44). Concordo que êsse lazer não seja necessàriamente voluntário nos países subdesenvolvidos, mas êsse já é outro problema.

4. Curiosos e evasivos são os comentários sôbre a minha definição do desenvolvimento. Curiosos, porque fazem inferências incorretas, que o texto não especifica, nem deixa a entrever, como a alegação de que a definição pretendesse ser temporária ou que visasse a ser modificada a qualquer momento; evasivos, porque Cintra Leite não a enfrenta diretamente, recorrendo a um dispositivo intelectual, invocando Friedman - e, diga-se de passagem: invocando-o mal, pois, em seu longo e fascinante ensaio sôbre a metodologia da ciência econômica, Friedman não analisa a problemática da definição de conceitos, mas se concentra, primordialmente, na maneira como hipóteses podem e devem ser construídas e aplicadas em economia.

Nesse contexto, seja-me permitido lembrar que a minha definição de desenvolvimento parte de dois pressupostos hipotéticos (p. 45), não temporários, e que ela é expressamente qualificada como diretriz hipotética para a formulação de idéias (p. 46). Isto por duas razões: a) para evitar que a jovem e inexperiente ciência do desenvolvimento seja enviesada, a priori, com conceitos e um instrumentário demasiadamente restritos; e b) para manter abertos os caminhos de uma possivel interpretação interdisciplinar da problemática e mecânica do desenvolvimento. 
Evidentemente, essas duas precauções não levam, necessàriamente, a uma boa definição. Contudo, se a definição não é do agrado do comentarista, por que êle não a contesta em si, talvez confrontando-a com outras definições, talvez demonstrando e justificando o que, a seu ver, ela deixa a desejar? Ao adotar êsse tipo de atitude crítica, mas construtiva, Cintra Leite poderia ter oferecido uma contribuição ao delicado problema da conceituação do desenvolvimento. No entanto, preferiu entrar em evasivas.

5. Pelo último êrro de interpretação do comentarista, assumo responsabilidade parcial. Ao reler a observação referente à elasticidade de preço, verifico que ela é, de fato, excessivamente lacônica para ser fàcilmente entendida. Em maior minúcia, o argumento é o seguinte: apesar do seu elevado grau de elasticidade de preço, a maioria dos bens produzidos pelo círculo interno é vendida com margens unitárias altas, ou seja: os produtores e distribuidores preferem auferir seus lucros vendendo um volume menor de mercadorias, mas a um preço alto, ao invés de tirar proveito da elasticidade de preço e das eventuais economias de escala que um alto volume de vendas lhes pudesse assegurar. Em outras palavras: o comportamento dos empresários tende a ser atípico em têrmos do homo economicus dos nossos livros-texto, se bem que não totalmente irracionais frente às condições peculiares (p. 58-59) que costumam caracterizar a demanda dos países subdesenvolvidos.

Se bem que essas minúcias não tenham sido explicitadas no texto, elas podem ser fàcilmente derivadas das considerações que precedem (p. 55-59) a observação sôbre a elasticidade de preços, sobretudo para o leitor treinado em raciocinar como economista.

6. Apenas uma das críticas de Cintra Leite não decorre necessàriamente da sua dificuldade de captação das idéias externadas no artigo. É correta a sua suposição de que o processo de qualificação educacional está implícito, ou decorre quase que forçosamente da tese central do artigo, sobretudo como recomendação político-econômica da ativação funcional e social. Concordo também com a afirmação do comentarista de que certos tipos de investimentos podem gerar - como de fato ge- 
raram - infra-estruturas educacionais, seja a la Hirschman ou outros, sobretudo de treinamento de mão-de-obra qualificada.

Todavia, contesto - e isso categòricamente - que o processo de educação, se algum efeito tem, é o de criar maiores tensões sociais. E algo estranho que um môço, que se dedica a educação, possa, a sério, externar um pensamento tão sombrio, quase que nihilista; e é lamentável que êsse pensamento seja o de um economista profissional.

Hoje existe uma vasta literatura especializada, na sua maioria de economistas, que pràticamente comprova (à base de dados reais, não apenas especulativos) que a educação não só contribui e substancialmente, à produtividade na aplicação dos fatôres de produção, como pode gerar, também, novos investimentos, sobretudo ao liberar recursos materiais, financeiros e primordialmente humanos, que seriam aplicados de maneiras ineficientes, não fôsse a educação.

Certamente, pelo menos um outro artigo seria necessário para analisar as possíveis implicações da educação sôbre o crescimento econômico dos países em desenvolvimento. Como a elaboração dêsse trabalho é impraticável a curto prazo, submeto uma seleção bibliográfica sôbre Educação e Desenvolvimento à apreciação dos leitores da Revista de Administração de Emprêsas, e, em especial, do meu colega Cintra Leite. Talvez a leitura de um ou outro dêsses trabalhos o inspire a dedicar-se com afinco ao assunto.

RAIMAR RICHERS

Educação e Desenvolvimento: Uma Seleção Bibliográfica

Adams, M. Latin America: Evolution or Explosion? Nova Iorque, Dodd, Mead \& Co., 1963. (Há uma edição brasileira na Zahar Editôres.)

Becker, G. S. Human Capital. New York, Columbia University Press, 1964.

BEEBY, C. E. The Quality of Education. In: Developing Countries. Harvard University Press, Cambridge, 1966. (Há uma edição brasileira da Zahar Editôres.)

BEEBX, C. E. Qualitative Aspects of Educational Planning. Paris, UNESCO, 1969. 
BowmaN, M. J. Human Capital: Concepts and Measures. In: Money, Growth and Methodology, Essays in Honor of Johan Akerman. Lund, 1961.

Bowman, M. J. \& Anderson, C. A. The Role of Education in Development. In: Development of Emerging Countries. The Brookings Institution, Washington D. C., 1962.

Bowman, M. J. et al. Readings in the Economics of Education. Paris, UNESCO, 1968.

Chesswas, J. D. Methodologies of Educational Planning for Developing Countries. Paris, UNESCO, 1969.

Cоomвs, P. M. La Crise Mondiale de L'Education: Analyse de Systèmes. Paris, Presses Universitaires de France, 1968.

CORreA, H. Quantitative Methodologies of Educational Planning. Scranton, Pa., International Textbook, 1969.

Curle, A. Education, Politics and Development. CER, $\mathrm{n}^{\circ} 3,1964$.

Denison, E. F. Education, Economic Growth, and Gaps in Information. JPE, outubro, 1962.

Denison, E. F. The Sources of Economic Growth in the United States. Nova Iorque, Commitee for Economic Development, Supplementary Paper, 1962 .

Denison, E. F. The Residual Factor in Economic Growth. Paris, OECD, 1963.

DenISON, E. F. The Contribution of Education to the Quality of Labor: Comment. AER, vol. $49, \mathrm{n}^{\circ}$ 5, dezembro, 1969.

De Vries, E. \& Echavarría, J. M. Social Aspects of Economic Development in Latin America. Paris, UNESCO, 19631. V. 1.

Echavarría, J. M. Filosofía, Educación y Desarrollo. México, Siglo Veintiuno, 1967.

ECLA. The Training of Human Resources in the Economic and Social Development of Latin America. EBLA, vol. 11, $\mathrm{n}^{\circ}$ 2, outubro, 1966.

GERLACH, K. Der Entwicklungsbeitrag von Bildungsinvestitionen unter Berücksichtigung verschiedener Entwicklungsstadien und - konzeptionen, Göttinger Wirtschafts und Sozialwissenschaftliche Studien, Vol. 8, Göttingen, 1969.

Harbison, F. H. Human Resources Development Planning in Modernising Economies. ILR, Vol. 85, $\mathrm{n}^{\circ} 5,1962$.

HARBISON, F. \& MYERS, C. A. Education, Manpower and Economic Growth. New York, McGraw-Hill, 1964. (Há uma edição brasileira da Editôra Fundo de Cultura.)

Kendrick, J. W. Productivity Trends in the United States. Princeton, 1961. KIKER, B. F. Human Capital in Retrospect. Columbia University of South Carolina, Bureau of Business and Economic Research, 1968.

LefF, N. H. Estudio del Problema Calidad-Cantidad en la Planeación Educacional, TE, Vol. 35, $\mathrm{n}^{\circ} 141$, janeiro/março, 1969.

LEWIS, W. A. Education and Economic Development, ISSJ, Vol. 14, $\mathrm{n}^{\circ} 4$, 1962.

Lyons, R. F. Problems and Strategies of Educational Planning, Lessons from Latin America. Paris, UNESCO, 1965. 
Machlup, F. The Production and Distribution of Knowledge in the United States. Princeton, Princeton University Press, 1962.

MACK, R. Ecological Processes in Economic Change: Models, Measurement, and Meaning, $A E R$, vol. 58, $\mathrm{n}^{\circ}$ 2, maio 1968.

Malassis, L. Dévelopment Économique et Programmation de L'Education Rurale. Paris, UNESCO, 1966.

MCClelland, D. Does Education Accelerate Economic Growth? EDCC, vol. 14, n³, abril 1966.

Moreira, J. R. Education and Development in Latin America. In: De Vries e Echavarría, 1963.

Morgan, J. \& David, M. H. Education and Income. QJE, vol. 77, agôsto 1963.

MYING, H. Social Flexibility, Social Discipline and Economic Growth. Paris, UNESCO/SS/SP/13, dezembro 1962 (mimeografado).

Nelson, B. H. Social Forces Influencing American Eudcation. Chicago, National Bureau of Economic Research, University of Chicago Press, 1961.

Nelson, R. R. Aggregate Production Functions and Medium-Range Growth Projections. $A E R$, vol. 54, $\mathrm{n}^{\circ}$ 5, setembro 1964.

Peaslee, A. L. Education's Role in Development, EDCC, vol. 17, $\mathrm{n}^{\circ}$ 13, abril 1969.

PEREIRA, L. Desenvolvimento, Trabalho e Educação. Rio de Janeiro, Zahar Editorres, 1967.

Pereira, L. \& Foracchi, M. M. Educação e Sociedade, Leituras de Sociologia da Educação. $4^{4}$ edição, São Paulo, Companhia Editôra Nacional, 1969.

Plaza, G. Os Problemas da Educação na América Latina, v. AdAms, M.

Prieto, L. B. Una Educación para América Latina. $A L$, ano $5, \mathrm{n}^{9} 3$, julhosetembro 1962.

Prieto, L. B. Educação para a América Latina. Ver: Adams, M. (coord.). Schultz, T. W. Capital Formation by Education. JPE, vol. 68, $\mathrm{n}^{\circ}$ 6, dezembro 1960.

Schultz, T. W. Investment in Human Capital. AER, vol. 51, março 1961.

Schultz, T. W. Reflections on Investment in Men. JPE, vol. 70, $\mathrm{n}^{\circ} 3$, Suplemento.

Schultz, T. W. Investment in Human Capital in Poor Countries. In: ZOOK, P, D. Foreign Trade and Human Capital. Dallas, 1962.

Schultz, T. W. The Economic Value of Education. New York, Columbia University Press, 1964. (Há uma edição brasileira da Zahar Editôres.)

ScHWARTZMAN, D. The Contribution of Education to the Quality of Labor 1929-1963. AER, vol. 58, n 3, Parte 1, junho 1968.

SCHWARTZMAN, D. The Contribution of Education to the Quality of Labor: Reply. AER, vol. 59, $\mathrm{n}^{\circ}$ 5, dezembro 1969.

Tinbergen, J. \& Bos, H. C. Econometric Models of Education: Some Applications. Paris, OECD, 1965.

UNESCO. Les Aspects Economiques et Sociaux de la Planification de L'Éducation. Paris, 1963 (coletânea). 
UNESCO. Manpower Aspects of Educational Planning, Problems for the Future. Paris, 1968 (coletânea).

UNESCO. Educational Planning, a World Survey of Problems and Prospects. Paris, 1970.

UNESCO/IIPE (1967 etc.), coleção de pequenos estudos sôbre a planificação da educação, publicada simultâneamente em inglês e francês pelo Institut International de Planification de L'Education. Até 1970 tinham sido publicados 10 títulos.

VERA, O. The Educational Situation and Requirements in Latin America, ver: De Vries e Echavarria (coord.).

\section{A ERA DO ADMINISTRADOR PROFISSIONAL}

Tão velha quanto o Estado, a Administração vem com êle evoluindo. O mundo moderno criou, nesse campo, especializações jamais imaginadas por épocas passadas, principalmente depois da 2. Guerra Mundial, com a arrancada dos países subdesen. volvidos. Por ser a Administração ainda negligenciada em nosso País como Ciência, e praticada sob formas empíricas que lhe retardam o processo de desenvolvimento, a Fundação Getúlio Vargas dedicou talvez o mais importante de seus esforços editoriais para dotar de literatura especializada adequada e abundante os que se dedicam à difícil tarefa da Administração em todos os seus níveis, a fim de contribuir para tornar realidade a era do administrador profissional, condição sine qua non para o nosso pleno desenvolvimento.

Pedidos para Fundação Getúlio Vargas, Praia de Botafogo, 188 , Caixa Postal 21.120, ZC-05, Rio, GB. 